\title{
Multivariate geostatistical analysis of stable isotopes in Portuguese varietal extra virgin olive oils
}

\author{
Nicasio T. Jiménez-Morillo ${ }^{\mathrm{a}, \mathrm{b}}$, Vera Palma ${ }^{\mathrm{b}}$, Raquel Garcia ${ }^{\mathrm{a}}$, José Alberto Pereira ${ }^{\mathrm{c}}$, \\ Cristina Barrocas Dias ${ }^{\mathrm{b}, \mathrm{d}}$, Maria João Cabrita ${ }^{\mathrm{a}, \mathrm{e}, *}$ \\ ${ }^{\text {a } M E D ~-~ M e d i t e r r a n e a n ~ I n s t i t u t e ~ f o r ~ A g r i c u l t u r e, ~ E n v i r o n m e n t ~ a n d ~ D e v e l o p m e n t, ~ U n i v e r s i d a d e ~ d e ~ E ́ v o r a, ~ P o ́ l o ~ d a ~ M i t r a, ~ A p . ~ 94, ~ 7006-554 ~ E ́ v o r a, ~ P o r t u g a l ~}$ \\ ${ }^{\mathrm{b}}$ HERCULES, Universidade de Évora, Palácio do Vimioso, 7000-089 Évora, Portugal \\ ${ }^{\mathrm{c}}$ Centro de Investigação de Montanha (CIMO), ESA, Instituto Politécnico de Bragança, Campus de Santa Apolónia, $5300-253$ Bragança, Portugal \\ ${ }^{\mathrm{d}}$ Departamento de Química, Escola de Ciências e Tecnologia, Universidade de Évora, Rua Romão Ramalho, 59, 7000 Évora, Portugal \\ ${ }^{\mathrm{e}}$ Departamento de Fitotecnia, Escola de Ciências e Tecnologia, Universidade de Évora, Núcleo da Mitra, Ap. 94, 7006-554 Évora, Portugal
}

\section{A R T I C L E I N F O}

\section{Keywords:}

Extra virgin olive oil

Geographic origin

Multi linear regression

Stable isotopes

Statistical analysis

\begin{abstract}
A B S T R A C T
Stable isotope contents of carbon, hydrogen and oxygen are known to reflect the geo-climatic conditions under which olives grown. This study aims to unravel the correlation between some of the main geographic variables and the isotopic composition of different Portuguese varietal extra virgin olive oil (EVOO) samples. Thus, the isotopic composition $\left(\delta^{13} \mathrm{C}, \delta^{18} \mathrm{O}\right.$ and $\left.\delta^{2} \mathrm{H}\right)$ of 38 EVOO samples from 11 olive varieties from 2 Portuguese regions (Alentejo and Trás-os-Montes) was studied using an elemental analyzer coupled to an isotope ratio mass spectrometry. Multivariate analysis indicated that bulk $\delta^{13} \mathrm{C}, \delta^{2} \mathrm{H}$ and $\delta^{18} \mathrm{O}$ values were enough to significantly $(P<0.05)$ predict altitude, latitude, longitude, temperature, rainfall, and sea distance. This work showed that the assessment of EVOO isotopic composition give information not only on the geographic origin, but also on the environmental conditions. To the best of our knowledge, this is the first report on bulk isotopic composition of Portuguese EVOOs.
\end{abstract}

\section{Introduction}

Olive oil is unique among other vegetable oils owing to the health benefits, nutritional properties and peculiar organoleptic characteristics. Since they are only mechanically extracted and consumed without any further refining process, the natural compounds are preserved contributing to its higher nutritional value [1]. Recent studies have described potential health benefits to some compounds that compose olive oil matrix, being considered as a functional food, which arouses a huge interest for its consumption [2].

Extra virgin olive oil (EVOO) is considered the top grade of olive oil, and with the commercial value of EVOO and the recent introduction on the market of high-quality monovarietal olive oils, it can lead to an increase of fraudulent practices, namely those related with the botanical and geographical origin of the olive oil [3]. Therefore, an especial attention has been given to EVOO authenticity, particularly on ascertain its geographic and varietal origin. The noticeable influence that geoclimatic conditions have on the organoleptic quality of olive oils [4], prompted the attempt to differentiate EVOO based on their geographic origin using suitable analytical methodologies. EVOO geographic denomination is not determined by the commonly used physico-chemical parameters [5] since they are not sufficiently accurate to enable this differentiation. Therefore, it is an imperative need the development of appropriate analytical tools combined with statistical methods to guarantee the authenticity and traceability of olive oils, preventing illicit practices and protecting both the producers and consumers. Nowadays, the evaluation of the stable isotope composition of the main bioelements ( $\mathrm{C}, \mathrm{N}, \mathrm{H}$ and $\mathrm{O}$ ) by isotope ratio mass spectrometry (IRMS) seems to be a powerful approach to ensure geographical origin of foodstuffs [6]. Stable isotope analysis of fatty acids was introduced in the $1970 \mathrm{~s}$ to study the pathways of lipid biosynthesis [7], but it was recently that IRMS technique has been applied to the

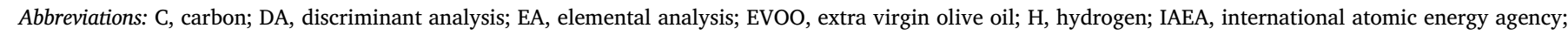

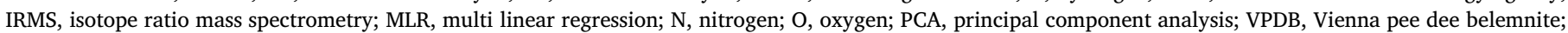
VSMOW, Vienna standard mean ocean water

* Corresponding author at: MED - Mediterranean Institute for Agriculture, Environment and Development, Universidade de Évora, Pólo da Mitra, Ap. 94, 7006-554 Évora, Portugal.

E-mail address: mjbc@uevora.pt (M.J. Cabrita). 
authentication of olive oils. Since stable isotopes can provide valuable information of geoclimatic characteristics of the production areas, as well as of the agricultural practices [8], they can be used as key markers of geographical origin, becoming a valuable approach in such kind of studies. Particularly, the $\mathrm{C}$ isotope composition $\left(\delta^{13} \mathrm{C}\right)$ of plant components (fruits, roots, leaves, etc.) is mainly related to the type of photosystem $\left(\mathrm{C}_{3}\right.$ and $\left.\mathrm{C}_{4}\right)$, as well as to several environmental and edaphic factors, like humidity, temperature, precipitation, salinity of soil, water stress, etc. [9]. On the other hand, the isotopic composition of $\mathrm{H}$ and $\mathrm{O}$ are indicators of the water uptake and evapotranspiration of the growing plant, which, in turn, are very sensitive to the geoclimatic conditions (latitude, longitude, altitude, temperature, etc.) of production areas $[10,11]$. Furthermore, $\delta^{2} \mathrm{H}$ and $\delta^{18} \mathrm{O}$ values are determined by the possible fractionation associated with the plant tissues biosynthesis pathways [12]. Owing to the conspicuous complexity of the data obtained with the different isotope analysis techniques, the use of multivariate statistical analyses, such as Principal Component Analysis (PCA), Partial Least Squares regression, Multi Linear Regression (MLR) and Discriminant Analysis, for both the interpretation of these data and the determination of geographical origin of olive oils $[13,14]$ is needed.

This study aimed to evaluate the suitability of stable isotope composition of the main bioelements ( $\mathrm{C}, \mathrm{H}$ and $\mathrm{O}$ ) for discriminating Portuguese varietal EVOO samples according to their geoclimatic conditions using multivariate statistical methods, such as PCA and MLR, for data evaluation.

\section{Materials and methods}

\subsection{Samples and experimental design}

A total of 38 well-catalogued EVOO (Olea europaea L.) samples from 11 different olive varieties (Arbequina, Blanqueta, Carrasquenha, Cobrançosa, Cordovil de Serpa, Galega Vulgar, Madural, Verdeal, Negrinha do Freixo, Picual and Verdeal Alentejana) produced in 12 different locations belonging to two well-differentiate Portuguese regions, Alentejo (Elvas, Mourão, Vidigueira, Serpa, Évora, Ferreira do Alentejo) and Trás-os-Montes (Freixo de Espada à Cinta, Alfandega da Fé, Macedo de Cavaleiros, Mirandela, Valpaços, and Vila Flor) (26 and 12 olive oil samples, respectively), were collected in November and December of 2016. For most of the samples, approximately $5 \mathrm{~kg}$ of each olive varieties were processed separately in an Abencor ${ }^{\circledR}$ system within $24 \mathrm{~h}$ from harvesting. Fruits were crushed with a hammer mill and the olive paste was malaxed at $25^{\circ} \mathrm{C}$ for $30 \mathrm{~min}$, in an olive paste mixer, finally the olive oil was separated by centrifugation. Other samples were taken directly from olive oil mills to avoid possible undeclared mixtures with olive oils from other cultivars and geographical origins before bottling. They were stored in dark-brown glass bottles at $20{ }^{\circ} \mathrm{C}$ in the dark. Each EVOO sample was geo-referenced, with data of latitude (UTM), longitude (UTM), altitude (m a.s.l.), sea distance $(\mathrm{km})$, mean annual temperature $\left({ }^{\circ} \mathrm{C}\right)$ and mean annual rainfall $(\mathrm{mm})$ respectively assigned (Table 1).

\subsection{Stable isotope analysis}

The carbon, hydrogen and oxygen isotope composition ratios $\left({ }^{13} \mathrm{C} /{ }^{12} \mathrm{C},{ }^{2} \mathrm{H} /{ }^{1} \mathrm{H}\right.$ and ${ }^{18} \mathrm{O} /{ }^{16} \mathrm{O}$, respectively) of EVOO samples were determined by elemental analysis/isotope ratio mass spectrometry (EA/ IRMS). The EA/IRMS system consisted of a Flash 2000 HT elemental analyzer (Thermo Scientific, Bremen, Germany) with two reactors: i) Combustion (C, N and S), and ii) Pyrolysis ( $\mathrm{H}$ and $\mathrm{O}$ ). The elemental analyzer is coupled by a ConFlo IV (Thermo Scientific) continuous flow open split interface to a Delta V Advantage isotope ratio mass spectrometer (Thermo Scientific). Carbon isotope analysis used helium as carrier gas at a flow rate of $80 \mathrm{~mL} / \mathrm{min}$, while for hydrogen isotope analysis the helium flow was set at $120 \mathrm{~mL} / \mathrm{min}$. EVOO samples $(0.5$ to $1 \mathrm{mg}$ ) were weighed in cups (IVA Analysentechnik GmbH \& Co. KG,
Meerbusch, Germany) made of tin for carbon and of silver for hydrogen and oxygen analysis. The cups were closed, folded, pressed to a small size and loaded in a MAS 200R (Thermo Scientific) automatic sampling carrousel. Appropriate calibration standards were prepared in the same manner and placed within batches of samples.

For carbon isotope analysis the cups were flush-combusted and flush-reduced concurrently under a helium carrier steam and oxygen pulse at $1020{ }^{\circ} \mathrm{C}$ in a quartz reactor filled with chromium oxide $\left(\mathrm{Cr}_{2} \mathrm{O}_{3}\right)$, silvered cobaltous-cobaltic oxide $\left(\mathrm{Ag}\left(\mathrm{Co}_{3} \mathrm{O}_{4}\right)\right)$ and reduced copper $(\mathrm{Cu})$. The gases were dried through a $10 \mathrm{~cm}$ long glass column filled with anhydrous magnesium perchlorate $\left(\mathrm{Mg}\left(\mathrm{ClO}_{4}\right)_{2}\right)$, and then directed through a $3 \mathrm{~m}$ long and $4 \mathrm{~mm}$ i.d. stainless steel gas chromatography column packed with Porapak stationary phase at $40{ }^{\circ} \mathrm{C}$ for the separation of $\mathrm{CO}_{2}$, which was analysed for its isotopic composition in the Delta V Advantage isotope ratio mass spectrometer. Pure $\mathrm{CO}_{2}$ gas was inserted into the He carrier flow as pulses of the reference gas $(250 \mathrm{~mL} / \mathrm{min})$.

For hydrogen and oxygen isotope ratios the samples were analysed using the pyrolysis reactor. This consists of an outer ceramic $\left(\mathrm{Al}_{2} \mathrm{O}_{3}\right)$ tube and an inner glassy carbon reactor tube filled with high-purity glassy carbon granulates, and wool of silver and quartz. The silver cups were dropped sequentially under a steam of helium into the reactor tube held at $1450{ }^{\circ} \mathrm{C}$. The produced pyrolysis gasses were passed through a $10 \mathrm{~cm}$ long glass column filled with a mixture of anhydrous magnesium perchlorate $\left(\mathrm{Mg}\left(\mathrm{ClO}_{4}\right)_{2}\right)$, to dry the gas, and Carbosorb, to trap $\mathrm{CO}_{2}$ generated during the pyrolysis reaction. The dry pyrolysis gasses were directed through a $3 \mathrm{~m}$ long and $4 \mathrm{~mm}$ i.d. stainless steel gas chromatography column packed with Porapack stationary phase at $70{ }^{\circ} \mathrm{C}$ for the separation of $\mathrm{H}_{2}$ and $\mathrm{CO}$. Hydrogen and oxygen were analysed for its isotopic composition on the Delta $\mathrm{V}$ Advantage isotope ratio mass spectrometer. Pure $\mathrm{H}_{2}$ and $\mathrm{CO}$ gas were inserted into the $\mathrm{He}$ carrier flow as pulses of the reference gas $(250 \mathrm{~mL} / \mathrm{min})$.

The stable isotope abundances are reported in the delta $(\delta)$ notation $\left(\delta^{13} \mathrm{C}, \delta^{2} \mathrm{H}\right.$ and $\left.\delta^{18} \mathrm{O}\right)$ in variations relative to an international standard. The isotope value was defined by Coplen in 2011 [15], according to equation (1):

$\delta^{i} E_{\text {sample }}=\frac{R(i E / j E)_{\text {sample }}}{(i E / j E)_{\text {stan dard }}}-1$

Where " $R$ " is the molar ratio of the heavy $\left({ }^{i} E\right)$ to light $\left({ }^{j} E\right)$ most abundant isotope of chemical element " $E$ " $\left({ }^{13} \mathrm{C} /{ }^{12} \mathrm{C},{ }^{2} \mathrm{H} /{ }^{1} \mathrm{H}\right.$ and ${ }^{18} \mathrm{O} /{ }^{16} \mathrm{O}$ ). The " $\delta$ " values are reported in milliurey (mUr). The stable isotope standard for carbon is the Vienna Pee Dee Belemnite limestone (VPDB), while for hydrogen and oxygen is the Vienna Standard Mean Ocean Water (VSMOW). The standards used were those recognized by the International Atomic Energy Agency (IAEA). The standard deviation of bulk $\delta^{13} \mathrm{C}, \delta^{2} \mathrm{H}$ and $\delta^{18} \mathrm{O}$ were $\pm 0.1,1.0$ and $0.5 \mathrm{mUr}$, respectively. Each sample was measured in duplicated $(n=2)$ to obtain its average and standard deviation.

\subsection{Statistical analysis}

Multivariate data treatments were carried out with the software Statgraphics Centurion XV, using the stable isotope values of carbon, hydrogen and oxygen of EVOO samples $(n=38)$ as independent variables. Principal component analysis (PCA) was used for simultaneous ordination of different geographic and climatic dependent variables and the $\delta^{13} \mathrm{C}, \delta^{2} \mathrm{H}$ and $\delta^{18} \mathrm{O}$ values (independent variables), illustrating their mutual relationships. Multiple linear regression (MLR) was applied considering the stable isotope composition as independent variables and the geographic and climatic factors as dependent variables. Spurious models due to overfitting were detected and discarded after repeating MLR models with fully randomized dependent variables. 


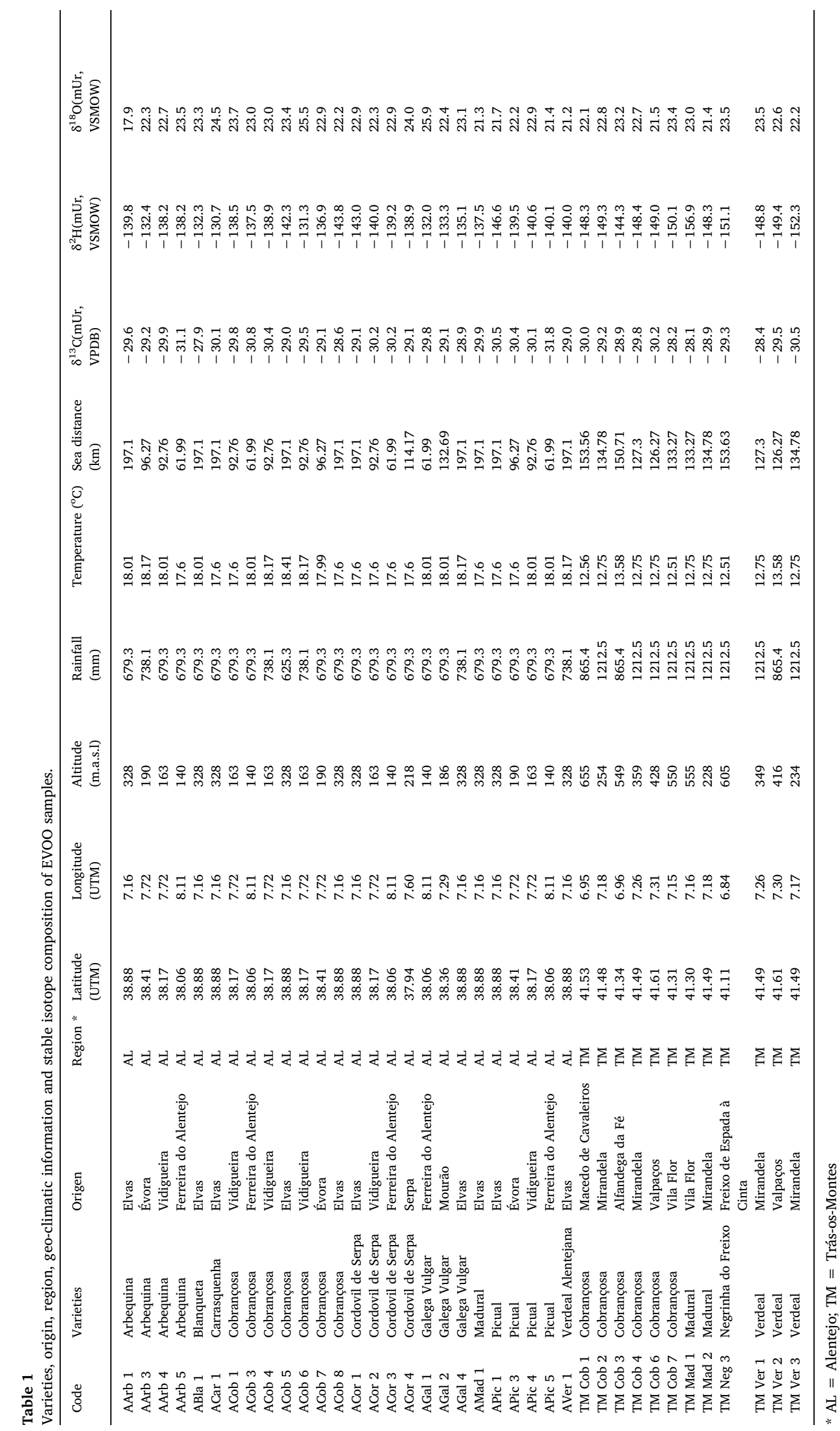


A)

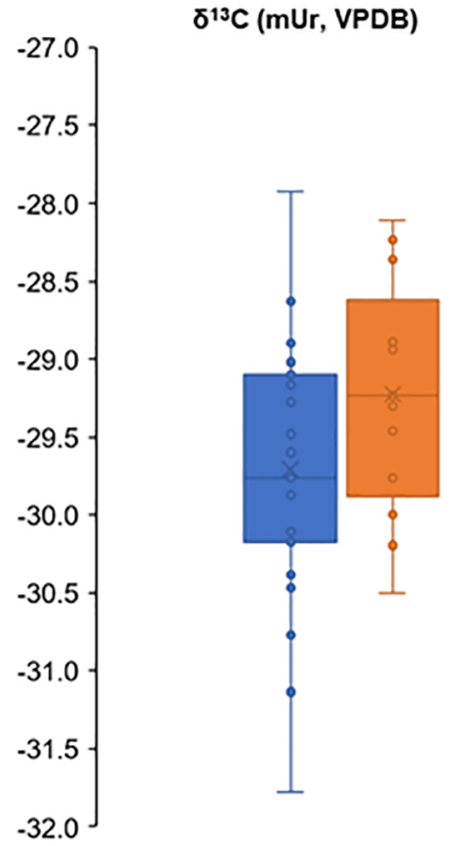

B)

$\delta^{18} \mathrm{O}(\%$, VSMOW $)$

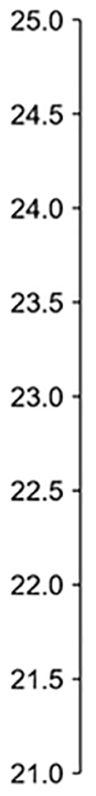

C)

$\delta^{2} \mathrm{H}(\%$, VSMOW $)$

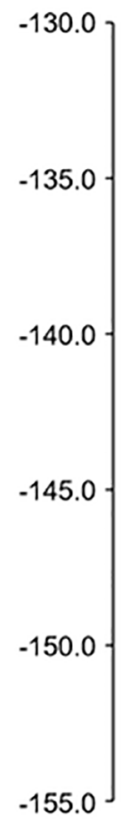

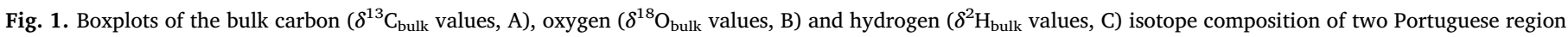
(Alentejo and Trás-os-Montes). Boxplots display the ranges, lower and upper quartiles (Q1, Q3), and the median (Q2).

\section{Results and discussion}

\subsection{Stable isotope analysis of EVOO samples}

The $\delta^{13} \mathrm{C}$ values (Fig. 1A) of EVOO samples, both from Alentejo and Trás-os-Montes regions, displayed a typical behavior of plants with $\mathrm{C}_{3}$ photosystem [16]. The ranges of $\delta^{13} \mathrm{C}$ values were different between the two main Portuguese regions, i.e., $3.9 \mathrm{mUr}$ for Alentejo (from -27.9 mUr to $-31.8 \mathrm{mUr}$ ) and $2.4 \mathrm{mUr}$ for Trás-os-Montes (from $-28.1 \mathrm{mUr}$ to $-30.5 \mathrm{mUr})$. Nevertheless, their mean values $\left(\delta^{13} \mathrm{C}_{\text {Alentejo }}=-\right.$ $29.6 \pm 0.6 \mathrm{mUr}, \delta^{13} \mathrm{C}_{\text {Trás-os-Montes }}=-29.3 \pm 0.6 \mathrm{mUr}$ ) showed no significant differences $(P>0.05)$. Although there was not a significant difference between regions, it was observed a little ${ }^{13} \mathrm{C}$-enrichment in Trás-os-Montes samples. This fact may be due either to the differences in the carbon isotopic composition between the subregions or to the variations in the olive varieties [17]. In fact, we can observe Fig. 2 (A and $\mathrm{B}$ ) that displays the $\delta^{13} \mathrm{C}$ values of EVOO samples both for different subregions and olive varieties. With respect to subregions, it is observed that EVOO samples cultivated in Vila Flor (Trás-os-Montes) were isotopically heavier than the rest one, while Ferreira do Alentejo (Alentejo) olive oils showed the lowest $\delta^{13} \mathrm{C}$ value. The $\delta^{13} \mathrm{C}$ values of plant cultured under irrigation proceedings display a more negative value $\left({ }^{13} \mathrm{C}\right.$-depletion) than that cultivated under drought conditions [18]. This idea may be related to the isotopic value of EVOO from Ferreira do Alentejo. However, we do not have this information. Concerning the varieties, Picual, collected in Alentejo, was isotopically lighter than the rest of varieties. Cobrançosa variety presents similar isotopic $C$ values either in Alentejo or Trás-os-Montes. Therefore, the little difference in carbon composition between these regions seems to be mainly related to the location of the olive tree cultivations and/or agricultural procedures (irrigation).

Similarly, to carbon isotope composition, the mean $\delta^{18} \mathrm{O}$ value (Alentejo $=23.0 \pm 0.7 \mathrm{mUr}$ and Trás-os-Montes $=22.7 \pm 0.7 \mathrm{mUr}$ ) showed no significant difference $(P>0.05)$ between the two regions studied (Fig. 1B). However, their ranges of values were different, i.e.,
3.2 mUr for Alentejo (from 24.5 to $21.3 \mathrm{mUr}$ ) and 2.1 for Trás-osMontes (from 23.5 to $21.4 \mathrm{mUr}$ ). This difference may be linked with the subregion and/or olive variety. In this case, the fact that EVOO samples cultivated in Trás-os-Montes show a $\delta^{18} \mathrm{O}$ value slightly lighter than that in Alentejo (Fig. 1B) may be due to the fact that the EVOOs produced in Valpaços, Macedo de Cavaleiros and Mirandela (Trás-osMontes) displayed a lighter isotopic composition of oxygen than the others (Fig. 2C). On the other hand, some olive varieties cultivated in Alentejo showed an isotopic composition heavier than that were cultivated in Trás-os-Montes (Fig. 2D and Table 1).

On the other hand, the mean $\delta^{2} \mathrm{H}$ value of the two regions of Portugal $\left(\delta^{2} \mathrm{H}_{\text {Alentejo }}=-137.2 \pm 2.2 \mathrm{mUr}, \delta^{2} \mathrm{H}_{\text {Trás-os-Montes }}=\right.$ $149.3 \pm 2.8 \mathrm{mUr})$ showed significant difference $(P<0.05)$, being Trás-os-Montes region more ${ }^{2} \mathrm{H}$-depleted than Alentejo one $\left(\delta^{2} \mathrm{H}_{\text {Trás-os- }}\right.$ Montes : from -152.3 to $-148.4 \mathrm{mUr}, \delta^{2} \mathrm{H}_{\text {Alentejo }}$ : from -146.6 to $-130.7 \mathrm{mUr}$ ). The ${ }^{2} \mathrm{H}$ composition, which reflects the type of water uptake by the plants during its growth, is highly linked (negatively and/ or positively) both to the climatic conditions of the production area, as well as to its geographical characteristics [19]. In our case, Trás-osMontes region shows higher elevation and rainfall amount than Alentejo one (Table 1). Nevertheless, Trás-os-Montes shows low seasonal temperatures (Table 1). The combination of low rainfall amount and high temperature causes a high evapotranspiration of the plants $[20,21]$, which is translated in an increase in the elimination of the light hydrogen isotope. Therefore, EVOO samples from Alentejo showed a heavier hydrogen composition. This result was also observed when it is studied the $\delta^{2} \mathrm{H}$ value of the different subregions (Fig. 2E, Table 1), since the EVOO samples cultivated in subregions located into Trás-osMontes were isotopically lighter than that are cultivated in subregions of Alentejo. Concerning olive varieties, there are significant difference among varieties (Fig. 2F). However, this difference may be directly related to culture location, because all olive varieties cultivated in Trásos-Montes regions (Cobrançosa, Madural, Negrinha do Freixo and Verdeal) showed lower ${ }^{2} \mathrm{H}$ composition than that cultured in Alentejo. For instance, the Cobrançosa variety is present in both regions; 


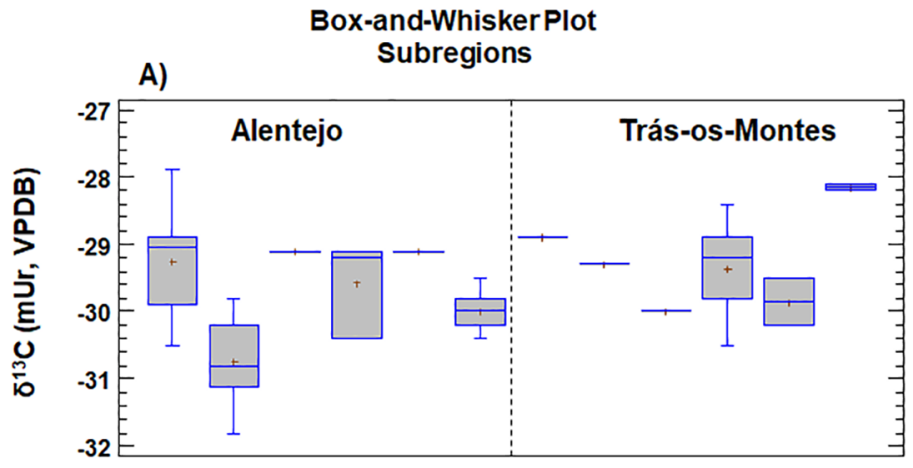

C)

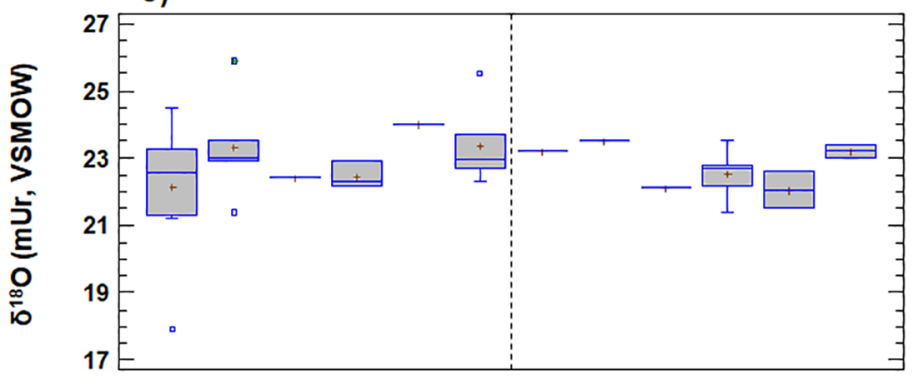

E)

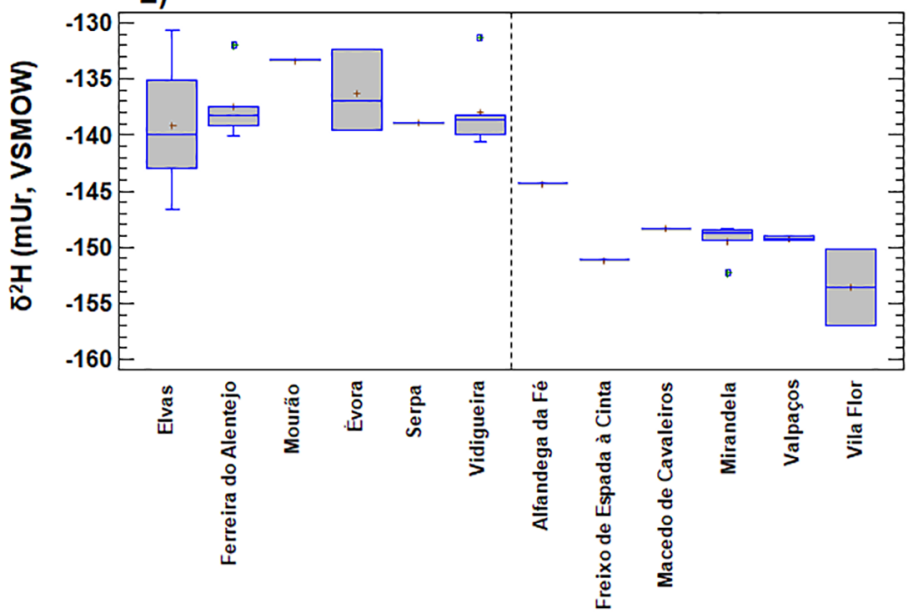

Box-and-Whisker Plot

Olive variety

B)

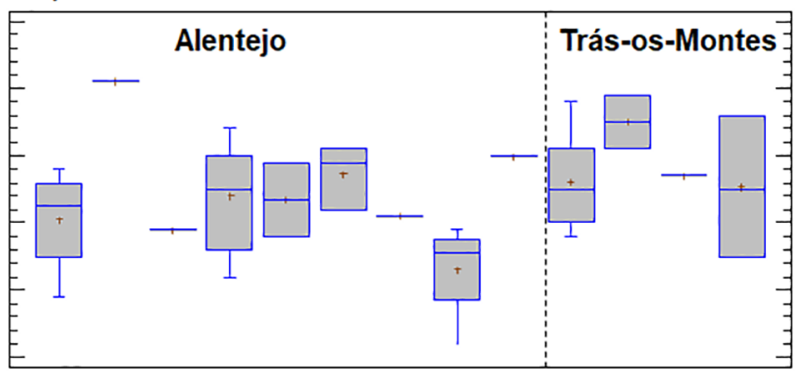

D)

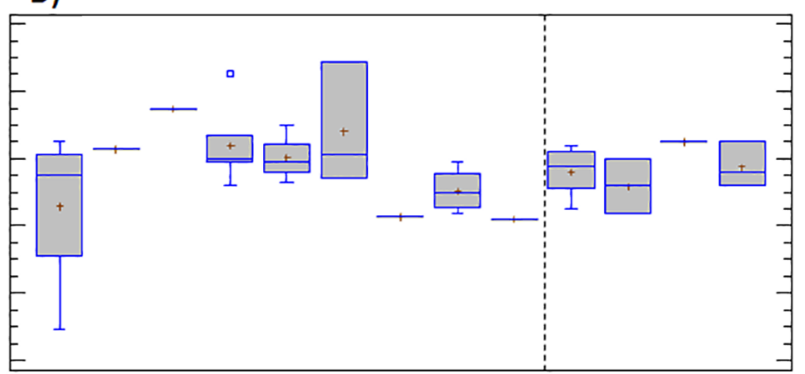

F)

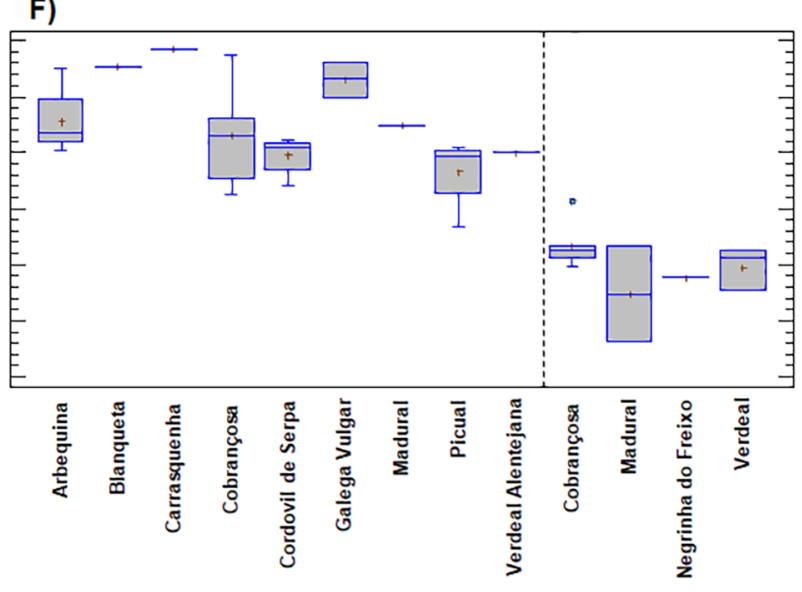

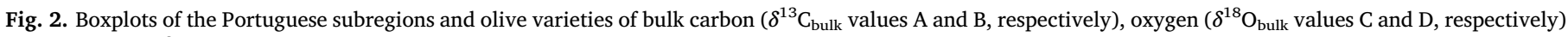

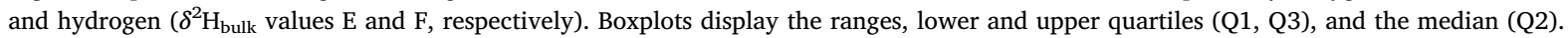

however, those cultivated in Trás-os-Montes showed a significant ${ }^{2} \mathrm{H}$ depletion compared with those from Alentejo. This may support the idea that the culture location is directly related to the isotopic value.

\subsection{Chemometric analysis}

Principal components analysis (PCA) was used to identify the possible positive and inverse correlation (angle of $0^{\circ}$ or $180^{\circ}$, respectively) between the stable isotope (carbon, hydrogen and oxygen) values and geographical and climatic variables (Fig. 3). Up to $75 \%$ of the total variance can be explained by two first components (component 1 : $55.52 \%$ and component 2: $20.41 \%$ ). The scatterplot of the loadings of PC-1 vs PC-2 showed that $\delta^{2} \mathrm{H}$ values were strongly positive correlated with climatic conditions, mainly temperature $\left(0^{\circ}\right)$, as well as the geographic longitude of the production area. Nevertheless, these are inversely correlated $\left(180^{\circ}\right)$ with latitude, altitude and, rainfall. With respect to sea distance, $\delta^{2} \mathrm{H}$ values showed no correlation $\left(90^{\circ}\right)$. Several researchers observed the same trend between hydrogen isotope and environmental factors. For example, Chiocchini et al., in 2016 [22] found that high altitude produced the ${ }^{2} \mathrm{H}$-depletion of organic samples.

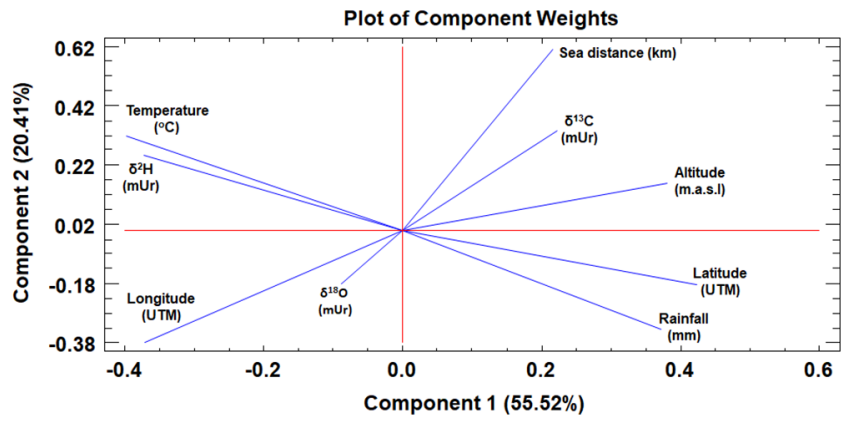

Fig. 3. Plot of components weights for the geographical variables and the stable isotope composition of carbon, hydrogen and oxygen $\left(\delta^{13} \mathrm{C}, \delta^{2} \mathrm{H}, \delta^{18} \mathrm{O}\right.$, respectively) of EVOO samples.

The positive correlation with temperature has recently been observed by Jiménez-Morillo et al. [23] using pyrolysis compound-specific isotope analysis. With respect to carbon isotope, it is highly correlated with sea distance (close to $0^{\circ}$ ) of the production area. However, the 

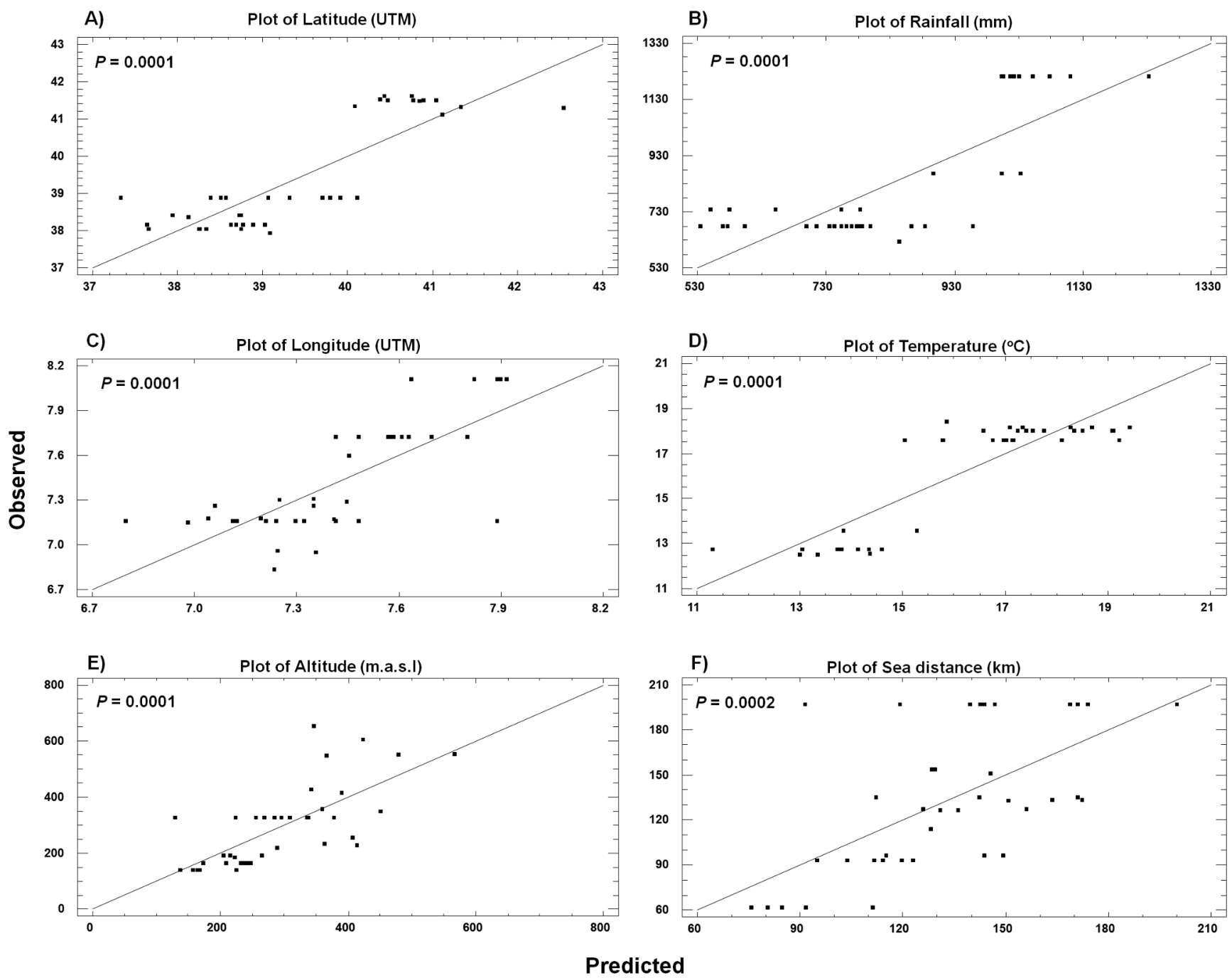

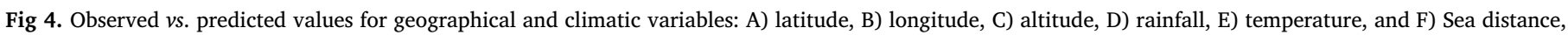
calculated by PLS regression using stable isotope values of EVOOs as predictors.

correlation with its altitude and latitude was not strong (higher than $45^{\circ}$ ). and rainfall. Furthermore, $\delta^{13} \mathrm{C}$ values were negatively correlated with longitude $\left(180^{\circ}\right)$. These correlations were also established by Camin et al. in 2010 [24]. The temperature and rainfall were not correlated $\left(90^{\circ}\right)$ with the carbon isotope composition of the EVOO samples. Oxygen isotope composition of EVOO samples was directly correlated with longitude (close to $0^{\circ}$ ) but inversely with sea distance $\left(180^{\circ}\right)$. This correlation was also observed by other researchers $[21,25,26]$, who observed that oxygen was linked with longitude (UTM) and distance from the sea $(\mathrm{km})$. These correlations were corroborated using multi linear regression (MLR). The MLR, exclusively using the stable isotope values (independent variables) of EVOO samples $(n=38)$ led to significant $(P<0.05)$ forecasting models for all geoclimatic (dependent) variables (i.e., latitude, longitude, altitude, rainfall, temperature and sea distance) from the total analysed samples. Fig. 4 plots the observed $v s$ predicted values of each models: a) latitude, b) longitude, c) altitude, d) rainfall, e) temperature, and f) sea distance. The model validation was confirmed by a strict criterion based on the comparing the MLR cross-validation tests (observed $v s$ predicted) with the alternative model computed from the fully randomized latent variables (latitude, longitude, altitude, rainfall, temperature and sea distance) from the 38 EVOO samples studied in this work. These models displayed a poor correlation $(P>0.05)$ with isotopic data (Figure S1 in supplementary information). Therefore, it is proved that a significant forecasting model is only possible with the real (experimental) values $[23,27,28]$. The MLR analysis of $\delta^{13} \mathrm{C}, \delta^{2} \mathrm{H}$ and $\delta^{18} \mathrm{O}$ values of different EVOO samples allowed to obtain the equations $2-7$ of the prediction model:

Latitude $=23.63+0.36 \times \delta^{13} \mathrm{C}--0.17 \times \delta^{2} \mathrm{H}$

Longitude $=1.37--0.24 \times \delta^{13} \mathrm{C}+0.02 \times \delta^{2} \mathrm{H}+0.07 \times \delta^{18} \mathrm{O}$

Altitude $=423.61+61.70 \times \delta^{13} \mathrm{C}--11.96 \times \delta^{2} \mathrm{H}$

Rainf all $=-2948.33--26.65 \times \delta^{2} H$

Temperature $=69.42+0.32 \times \delta^{2} \mathrm{H}--0.33 \times \delta^{18} \mathrm{O}$

Sea dis $\tan c e=1335.06+29.78 \times \delta^{13} \mathrm{C}--14.18 \times \delta^{18} \mathrm{O}$

Only those independent variables whose value of $P$ has been $<0.05$ have been taken into account for the creation of the models. Therefore, there are geoclimatic variables that displayed in their model one or two independent variables (stable isotope composition).

The existence of correlation $(P<0.05)$ between stable isotope values and dependent variables (climatic and geographical) may explain why there was a significant difference between two Portuguese regions. On the other hand, it could say that the combined use of ${ }^{2} \mathrm{H}$, ${ }^{13} \mathrm{C}$ and ${ }^{18} \mathrm{O}$ isotopic composition gives a valuable and precise information for the assessing of geographic origin of Portuguese EVOO samples, which is a very powerful tool, which could help to fight against food-fraud suffered by EVOO sector in Portugal. As far as 
authors are aware, this work is the first one that use, in combination, bulk isotopic composition $\left(\delta^{2} \mathrm{H}, \delta^{13} \mathrm{C}\right.$ and $\left.\delta^{18} \mathrm{O}\right)$ and multivariate statistical analysis (PCA and MLR), to assess the geographic origin of Portuguese EVOOs.

\section{CRediT authorship contribution statement}

Nicasio T. Jiménez-Morillo: Methodology, Formal analysis, Investigation, Writing - original draft. Vera Palma: Investigation. Raquel Garcia: Investigation. José Alberto Pereira: Investigation. Cristina Barrocas Dias: Investigation, Writing - review \& editing. Maria João Cabrita: Conceptualization, Resources, Writing - review \& editing, Supervision, Project administration.

\section{Declaration of Competing Interest}

The authors declare that they have no known competing financial interests or personal relationships that could have appeared to influence the work reported in this paper.

\section{Acknowledgments}

This work was funded by European Regional Development Fund (FEDER) and National Funds through Foundation for Science and Technology (FCT) under Project "Por3O - Portuguese Olive Oil Omics for traceability and authenticity - PTDC/AGRPRO/2003/2014, and by National Funds through FCT - Foundation for Science and Technology under the Projects UIDB/05183/2020 and UID/AGR/00690/2019. Pedro N. Jiménez-Morillo is acknowledged for statistical assistance.

\section{Appendix A. Supplementary data}

Supplementary data to this article can be found online at https:// doi.org/10.1016/j.microc.2020.105044.

\section{References}

[1] C. Campestre, G. Angelini, C. Gasbarri, F. Angerosa, The Compounds Responsible for the Sensory Profile in Monovarietal Virgin Olive Oils, Molecules 22 (2017) 1833, https://doi.org/10.3390/molecules22111833.

[2] Nancy B. Ray, Kyle D. Hilsabeck, Tom C. Karagiannis, D. Elizabeth McCord, The Role of Functional Food Security in Global Health, Elsevier, 2019, pp. 623-637, , https://doi.org/10.1016/B978-0-12-813148-0.00036-0.

[3] R. Garcia, N. Martins, M.J. Cabrita, Putative markers of adulteration of extra virgin olive oil with refined olive oil: Prospects and limitations, Food Res. Int. 54 (2013) 2039-2044, https://doi.org/10.1016/j.foodres.2013.05.008.

[4] I.M. Abu-Reidah, M. Yasin, S. Urbani, M. Sevili, G. Montedoro, Study and characterization of Palestinian monovarietal Nabali virgine olive oils from northern west Bank of Palestine, Food Research International 54 (2013) 1959-1964, https:// doi.org/10.1016/j.foodres.2013.09.004.

[5] R. Aparicio, M.T. Morales, R. Aparicio-Ruiz, N. Tena, D.L. García-González, Authenticity of olive oil: Mapping and comparing official methods and promising alternatives, Food Res. Int. 54 (2013) 2025-2038, https://doi.org/10.1016/j. foodres.2013.07.039.

[6] F. Camin, M. Boner, L. Bontempo, C. Fauhl-Hassek, S.D. Kelly, J. Riedl, A. Rossmann, Stable isotope techniques for verifying the declared geographical origin of food in legal cases, Trends Food Sci. Technol. 61 (2017) 176-187, https:// doi.org/10.1016/j.tifs.2016.12.007.

[7] M.J. De Niro, S. Epstein, Mechanism of Carbon Isotope Fractionation Associated with Lipid Synthesis, Science 197 (1977) 261-263.

[8] A.K. Styring, M. Ater, Y. Hmimsa, R. Fraser, H. Miller, R. Neef, J.A. Pearson, A. Bogaard, Disentangling the effect of farming practice from aridity on crop stable isotope values: A present-day model from Morocco and its application to early farming sites in the eastern Mediterranean, The Anthropocene Review 3 (2016) 2-22, https://doi.org/10.1177/2053019616630762.

[9] G. Hartman, A. Danin, Isotopic values of plants in relation to water availability in the Eastern Mediterranean region, Oecologia 162 (2010) 837-852, https://doi.org/ 10.1007/s00442-009-1514-7.

[10] R.J. Brooks, H.R. Barnard, R. Coulombe, J.J. McDonnell, Ecohydrologic separation of water between trees and streams in a Mediterranean climate, Nat. Geosci. 3 (2010) 100-104, https://doi.org/10.1038/ngeo722.

[11] S.D. Kelly, C. Rhodes, Emerging techniques in vegetable oil analysis using stable isotope ratio mass spectrometry, Grasas Aceites 53 (2002) 34-44, https://doi.org/ 10.3989/gya.2002.v53.i1.28.

[12] H.L. Schmidt, R.A. Werner, W. Eisenreich, Systematics of ${ }^{2} \mathrm{H}$ patterns in natural compounds and its importance for the elucidation of biosynthetic pathways, Phytocheistry Reviews 2 (2003) 61-85, https://doi.org/10.1023/B:PHYT. 0000004185.92648.ae.

[13] A.M. Gómez-Caravaca, R.M. Maggio, L. Cerretani, Chemometric applications to assess quality and critical parameters of virgin and extra-virgin olive oil, A review, Analytica Chimica Acta 913 (2016) 1-21, https://doi.org/10.1016/j.aca.2016.01. 025.

[14] A. Kritioti, G. Menexes, C. Drouza, Chemometric characterization of virgin olive oils of the two major Cypriot cultivars based on their fatty acid composition, Food Res. Int. 103 (2018) 426-437, https://doi.org/10.1016/j.foodres.2017.10.064.

[15] T.B. Coplen, Guidelines and recommended terms of expression of stable-isotoperatio and gas-ratio measurement results, Rapid Commun. Mass Spectrom. 25 (2011) 2538-2560, https://doi.org/10.1002/rcm.5129.

[16] J.E. Spangenber, Bulk C, H, O, and fatty acid C stable isotope analyses for purity assessment of vegetable oils from the southern and northern hemispheres, Rapid Commun. Mass Spectrom. 30 (2016) 2447-2461, https://doi.org/10.1002/rcm. 7734.

[17] G. Bianchi, F. Angerosa, L. Camera, F. Reniero, C. Anglani, Stable carbon isotope ratios (carbon-13/carbon-12) of olive oil components, J. Agric. Food. Chem. 41 (1993) 1936-1940, https://doi.org/10.1021/jf00035a024.

[18] M.A. Aramendía, A. Marinas, J.M. Marinas, E. Sánchez, F.J. Urbano, C. Guillou, J.M. Moreno Rojas, M. Moalem, L. Rallo, A nuclear magnetic resonance $\left({ }^{1} \mathrm{H}\right.$ and ${ }^{13} \mathrm{C}$ ) and isotope ratio mass spectrometry $\left(\delta^{13} \mathrm{C}, \delta^{2} \mathrm{H}\right.$ and $\left.\delta^{18} \mathrm{O}\right)$ study of Andalusian olive oils, Rapid Commun. Mass Spectrom. 24 (2010) 1457-1466, https://doi.org/ 10.1002/rcm.4538.

[19] L. Bontempo, F. Camin, R. Larcher, G. Nicolini, M. Perini, A. Rossmann, Coast and year effect on $\mathrm{H}, \mathrm{O}$ and $\mathrm{C}$ stable isotope ratios of Tyrrhenian and Adriatic italian olive oils, Rapid Communications in Mass Spectrometry 23 (2009) 1043-1048, https://doi.org/10.1002/rcm.3968.

[20] K.F. Kaseke, L. Wang, H. Wanke, V. Turewicz, P. Koeniger, An Analysis of Precipitation Isotope Distributions across Namibia Using Historical Data, PLoS ONE 11 (2016) e0154598, , https://doi.org/10.1371/journal.pone.0154598.

[21] I. Clark, P. Fritz, Environmental Isotopes in Hydrogeology, Lewis Publishers, Boca Raton, New York, 1997, p. 328.

[22] F. Chiocchini, S. Portarena, M. Ciolfi, E. Brugnoli, M. Lauteri, Isoscapes of carbon and oxygen stable isotope compositions in tracing authenticity and geographical origin of Italian extra-virgin olive oils, Food Chemistry 202 (2016) 291-301, https://doi.org/10.1016/j.foodchem.2016.01.146.

[23] N.T. Jiménez-Morillo, M.J. Cabrita, C. Barrocas-Dias, F.J. González-Vila, J.A. González-Pérez, Pyrolysis-compound-specific hydrogen isotope analysis $(\delta 2 \mathrm{H}$ Py-CSIA) of Mediterranean olive oils, Food Control 110 (2020) 107023, , https:// doi.org/10.1016/j.foodcont.2019.107023.

[24] F. Camin, R. Larcher, M. Perini, L. Bontempo, D. Bertoldi, G. Gagliano, G. Nicolini, G. Versini, Characterisation of authentic Italian extra-virgin olive oils by stable isotope ratios of C, O and $\mathrm{H}$ and mineral composition, Food Chemistry 118 (2010) 901-909, https://doi.org/10.1016/j.foodchem.2008.04.059.

[25] X. Feng, S. Epstein, Carbon isotopes of trees from arid environments and implications for reconstructing atmospheric $\mathrm{CO}_{2}$ concentration, Geochim. Cosmochim. Acta 59 (1995) 2599-2608, https://doi.org/10.1016/0016-7037(95)00152-2.

[26] T.R. Peng, K.Y. Chen, W.J. Zhan, W.C. Lu, L.T.J. Tong, Use of stable water isotopes to identify hydrological processes of meteoric water in montane catchments, Hydrol. Process. 29 (2015) 4957-4967, https://doi.org/10.1002/hyp.10557.

[27] J.M. De la Rosa, M.A. Jiménez-González, N.T. Jiménez-Morillo, H. Knicker, G. Almendros, Quantitative forecasting black (pyrogenic) carbon in soils by chemometric analysis of infrared spectra, J. Environ. Manage. 251 (2019) 109567, https://doi.org/10.1016/j.jenvman.2019.109567.

[28] M.A. Jiménez-González, A.M. Álvarez, P. Carral, G. Almendros, Chemometric assessment of soil organic matter storage and quality fromhumic acid infrared spectra, Sci. Total Environ. 685 (2019) 1160-1168, https://doi.org/10.1016/j.scitotenv. 2019.06.231. 